\title{
PIBID e o ensino da química: um olhar hermenêutico dialético
}

\author{
PIBID and the teaching of chemistry: a hermeneutic-dialectical \\ view
}
PIBID y la ensenanza de la química: uma mirada hermenéutica dialéctica

\author{
Alida Beatrice Gomes Santos (alidabeatrice08@ gmail.com) \\ Universidade Federal Rural de Pernambuco - UFRPE \\ Crislaine Maria da Silva (crismariasilvacg@gmail.com) \\ Universidade Federal Rural de Pernambuco - UFRPE
}

Resumo: O presente artigo busca avaliar como o PIBID tem contribuído no processo de ensinagem de conceitos abstratos na disciplina de química, tendo como objetivo principal compreender como os pibidianos auxiliam na construção do conhecimento de conceitos na disciplina de química. A metodologia escolhida foi a interativa descrita por Oliveira (2016), e como instrumentos de coleta de dados utilizamos a Sequência Didática Interativa, nos resultados e discursões criamos categorias teóricas (relação teoria e prática; contato inicial com a sala de aula; despertar o interesse dos alunos e empíricas) e como categorias empíricas utilizamos as questões criadas para coleta de dados, para a análise de dados escolhemos a Análise Hermenêutica-Dialética descrita por que consegue apreender de forma mais aproximada a realidade dos pesquisados.

Palavras-chave: PIBID; ensino de química; hermenêutica-dialética.

\begin{abstract}
This article seeks to assess how PIBID has contributed to the process of teaching abstract concepts in the discipline of chemistry, with the main objective of understanding how pibidians help in the construction of knowledge of concepts in the discipline of chemistry. The chosen methodology was the interactive one described by Oliveira (2016), and as instruments of data collection we used the Interactive Didactic Sequence, in the results and discourses we created theoretical categories (relation between theory and practice; initial contact with the classroom; arousing interest students and empirical) and as empirical categories we use the questions created for data collection, for data analysis we choose the Hermeneutic-Dialectic Analysis described because it manages to more closely apprehend the reality of the respondents.
\end{abstract}

Palavras-chave traduzidas: PIBID; teaching chemistry; hermeneutics-dialectic.

Resumen: Este artículo busca evaluar cómo PIBID ha contribuido al proceso de enseñanza de conceptos abstractos en la disciplina de la química, con el objetivo 
principal de comprender cómo los pibidianos ayudan en la construcción del conocimiento de conceptos en la disciplina de la química. La metodología elegida fue la interactiva descrita por Oliveira (2016), y como instrumentos de recolección de datos utilizamos la Secuencia Didáctica Interactiva, en los resultados y discursos creamos categorías teóricas (relación entre teoría y práctica; contacto inicial con el aula; despertar interés de los estudiantes y empírico) y como categorías empíricas utilizamos las preguntas creadas para la recolección de datos, para el análisis de datos optamos por el Análisis Hermenéutico-Dialéctico descrito porque logra aprehender la realidad de los sujetos más de cerca.

Palabras clave: PIBID; enseñar química; hermenéutica-dialéctica.

\section{INTRODUÇÃO}

O ensino de química no Brasil está tendo grandes avanços nestes últimos anos, os pesquisadores da área, como Cardoso e Colinvaux (2000), Veiga (2012), Silva (2013), entre outros, discutem a necessidade de ser trabalhado de forma mais atenta o fato de que os alunos do ensino médio apresentarem algumas dificuldades em visualizar a ciência, especificamente a química, considerando-a como uma ciência abstrata, não conseguindo compreender os conteúdos trabalhados em sala de aula.

Neste contexto, é importante que os professores busquem cada vez mais relacionar a teoria com a prática, contextualizar o conteúdo com o meio em que o aluno é inserido, visando formar um cidadão crítico e reflexivo, para que ao se deparar em diversas situações saibam como resolvê-las através de embasamentos científicos.

De acordo com a ideia, segundo Branco e Zanatta (2021), a educação desempenha uma função fundamental na vida dos indivíduos e na construção da sociedade. Sobretudo, por ser um instrumento de promoção da justiça social e também ter influência direta na cultura e no modo de vida das pessoas. Desse modo, o campo educacional configura-se como objeto de interesse de diferentes grupos, geralmente com interesses antagônicos. Nesse contexto, de um lado situam-se os educadores e educandos, e de outro os governos, as instituições particulares e as organizações multilaterais visando suprir suas demandas, por meio de ideologia hegemônica, especialmente para a manutenção do poder e a expansão do capital.

Desta forma, o ensino de química tem visado cada vez mais compreender os conhecimentos empíricos dos alunos, detectando quais são seus conhecimentos prévios 
e sua bagagem conceitual acerca dos conteúdos a serem discutidos em sala de aula, para após este momento conseguir escolher qual metodologia deve ser utilizada para conseguir mediar o conteúdo científico da melhor forma.

Freire (2015), afirma que a criticidade, a reflexividade, a pesquisa e a autonomia são indispensáveis à formação de um educador progressista. Formosinho (2009) defende a formação de professores como aprendizagem profissional da ação docente. Este caracteriza cinco tipos diferentes de concepções do que é ser professor: missionária, militante, laboral, burocrática e romântica.

Diante deste contexto, este artigo tem a finalidade de avaliar como o PIBID tem contribuído no processo de ensino de conceitos abstratos na disciplina de química. Para compreendermos melhor, é importante ressaltar que a ensinagem este é o termo cunhado por Anastasiou, para se referir a uma prática social, crítica e complexa em educação entre professor e estudante, "englobando tanto a ação de ensinar quanto a de apreender" (ANASTASIOU; ALVES, 2004, p. 15).

Para darmos conta da pesquisa de modo coerente temos como objetivo principal ver como os pibidianos auxiliam na construção do conhecimento de conceitos na disciplina de química e utilizamos a Sequência didática Interativa como instrumento de coleta de dados.

\section{FUNDAMENTAÇÃO TEÓRICA}

Nesta sessão abordaremos, estudos que servem para uma compreensão mais aprofundada a cerca do Programa Institucional de Bolsas de Iniciação à Docência (PIBID) no ensino de química, além de serem relatadas as dificuldades no ensino de concepções de conteúdos abstratos da química. Iniciaremos falando sobre ensino de química de acordo com a literatura.

\section{Ensino de química}

No Brasil a disciplina de Química começou a ser ministrada no ensino regular somente a partir de 1931, após a reforma educacional Francisco Campos. De acordo com documentos da época, o ensino de Química tinha por objetivos dotar o aluno de 
conhecimentos específicos, despertar-lhe o interesse pela ciência e mostrar a relação desses conhecimentos com o cotidiano (MACEDO; LOPES, 2002).

Segundo Schnetzer (1981) o ensino de química

\begin{abstract}
tem por fim proporcionar aos alunos o conhecimento da composição e da estrutura íntima dos corpos, das propriedades que delas decorrem e das leis que regem as suas transformações, orientando-o por tirocínio lógico e científico de valor educativo e coordenando-o pelo interesse imediato da utilidade, e com as aplicações da vida quotidiana Reforma Francisco Campos - 1931 a 1941 (SCHNETZLER, 1981, p.10)
\end{abstract}

A disciplina de química "deve possibilitar ao aluno a compreensão tanto dos processos químicos em si quanto da construção de um conhecimento científico em estreita relação com as aplicações tecnológicas e suas implicações ambientais, sociais, políticas e econômicas" (PCNEM, 1999, p.31).

Diante deste contexto, percebemos que é importante estudar a química, pois esta disciplina possibilita grande influência na vida cotidiana das pessoas, ultrapassando a visão de que a química se limita apenas pesquisas de laboratórios e de produção industrial, mas sim se destina a explicar os fenômenos que ocorrem no contexto em que estamos inseridos (USBERCO, 2007). Sendo assim, é importante que ao ser trabalhada a disciplina de química o professor contextualize o conteúdo estudado com a realidade dos estudantes, o que mostra que ela está presente em nossas vidas. Para que isto aconteça, o professor de química precisa utilizar metodologias que facilitem o processo de ensino e aprendizagem, ou seja, adotar estratégias de ensino para aprimorar: o aprender a conhecer, o aprender a fazer, o aprender a conviver e o aprender a ser (PRIESS, 2012).

Vale resaltar, que o para que o ensino desta disciplina seja bem efetivado deve abandonar-se as aulas baseadas na simples memorização de nomes e fórmulas, tornando-as vinculadas aos conhecimentos e conceitos do dia-a-dia do alunado. (CHASSOT, 1990).

\title{
Conteúdos abstratos de química
}

Segundo Silva (2013) o ensino de Química é um constante desafio para os professores, isto ocorre devido muitos alunos desaprovarem a disciplina e considerarem os assuntos trabalhados na química um tanto abstratos (SOUZA; LEITE; LEITE, 2015), 
requerendo uma atenção maior dos estudantes, dificultando ainda mais o processo de ensino e aprendizagem.

Para que isto seja amenizado Veiga (2012) diz que existem diferentes tecnologias usadas para o ensino de Química que proporcionam aos discentes e docentes desde pesquisas a simulações, e que é possível, que a partir destas sejam confeccionar instrumentos de baixo custo que tornem o ensino-aprendizagem na química mais interessante para os alunos.

De acordo com Cardoso e Colinvaux (2000) a forma como os conteúdos são ministrados, influenciam diretamente no processo de desmotivação do aluno, pois a quantidade excessiva de conteúdos, muitas vezes abstratos ou ensinados de maneira confusa e superficial, colabora com os fatores que desmotivam o estudo da química.

Neste contexto, segundo Bernardes e Moura (2009) alguns pesquisadores defendem o uso sistemático de analogias no processo ensino e aprendizagem para uma efetiva significação dos conteúdos escolares, principalmente aqueles mais abstratos, a partir das mediações simbólicas geradas pelo processo relacional entre o estranho e o familiar, entre o conhecido e o desconhecido.

As analogias precisam ser utilizadas no processo de construção do conhecimento científico, pois gera grande impacto no ensino e aprendizagem de ciências na educação básica, já que a ciência procura explicar a natureza, através de representações teóricas que constituem sistemas epistêmicos de explicação, ou seja, os próprios conceitos e teorias são modelos com suas potencialidades e limitações (NÚÑEZ et al., 2003).

Logo, é importante ressaltar que para que haja um ensino da disciplina de química bem efetivado o professor precisa sobretudo aproximar o contexto em que o aluno está inserido aos conceitos de química, utilizar metodologias interativas para que o aluno seja ativo na sua construção de conhecimento, e também recorra a recursos didáticos e tecnológicos auxiliar este processo. Pois, segundo Vasconcelos e Rocha (2016) existem evidências de que a capacidade que os alunos têm para visualizar e resolver um problema é aumentada quando os mesmos conseguem contextualizar o problema com situações da sua vida.

\section{Formação inicial de professores}


A formação inicial de professores tem sido pautada como um dos desafios na educação, não apenas pensando na formação adequada e efetiva desses profissionais, como também no que concernem às perspectivas a serem encontradas no âmbito educacional por esses futuros docentes (CUSTODIO, 2012; SILVA, 2017).

Freire (1999) se refere à formação docente como um fazer permanente que se refaz constantemente na pratica. Este afirma que "quem ensina aprende ao ensinar. E quem aprende ensina ao aprender".

Desse modo, a formação inicial é uma etapa importante na constituição de um profissional, sendo o local de aprendizagem e aquisição dos conhecimentos sobre a docência (BELO, 2012), o que possibilita que os professores em formação conheçam as realidades da profissão, bem como sobre a prática docente.

Nesse contexto no processo de formação é essencial envolver todas as fases de atuação do trabalho docente, pois o professor em formação possui necessidades de evoluir, avaliar e aprender sobre seu próprio ensino (GARCÍA, 2010; CUNHA et al., 2016). Dessa maneira, é necessário que os professores iniciantes consigam refletir sobre a própria prática, assim como de outros professores, possibilitando a construção da sua identidade docente.

Segundo Moretto et al., (2021) apontam como obstáculo a formação fragmentada, linear e descontextualizada dos profissionais que trabalham na educação, além das condições de trabalho a que estão submetidos, como organização de grades curriculares, falta da manutenção dos equipamentos, falta de motivação própria, entre tantos outros fatores. Ensinar de maneira interdisciplinar é um desafio, primeiramente, por desconstruir o papel do professor transmissor do conteúdo, o professor deve ser reflexivo, colaborativo, atuar como mediador da troca de ideias e conhecimentos entre os alunos.

Tardif (2008) explica que a formação para o ensino não pode limitar-se a conhecimentos e competências; deve envolver também valores,compromissos normativos e convicções éticas. A formação de professores como aprendizagem profissional da ação docente, ou seja, do exercício da docência. E ao desvelar concepções conflitantes de professor, contribui para pensarmos em alguns 
possíveis estereótipos formativos presentes nas instituições formadoras de professores (FORMOSINHO, 2009).

\section{PIBID na formação inicial}

O PIBID é um programa que promove mudanças positivas na formação inicial dos licenciandos contemplados, de forma que possibilita aos futuros profissionais docentes reflexões sobre o campo da educação e também possibilita que os mesmos compreendam a realidade escolar na prática (PAREDES; GUIMARÃES, 2012). O PIBID tem como objetivo a inclusão das diversas atividades que proporcionam a aprendizagem a partir de diferentes instrumentos e metodologias de ensino, estimulando a docência através de intervenções realizadas em escolas participantes.

Para Massena e Siqueira (2016), Programas como o PIBID, bem como os estágios realizados durante a formação inicial docente, proporciona uma maior integração entre as instituições de Educação Básica e as instituições formadoras, assim como a integrações entre a teoria e prática da docência. Desse modo, a participação em Programas de Iniciação à Docência, estágios supervisionados obrigatórios ou não, são oportunidades encontradas pelos futuros docentes para vivenciarem a teoria na prática.

O subprojeto do curso de Química, ofertado pela CAPES em 2009, teve como proposta elaborar e desenvolver atividades nas escolas selecionadas, que contemplassem a articulação entre a leitura, a contextualização e a experimentação no Ensino de Química.

\section{Relação teoria e prática}

Na graduação os alunos são expostos a conteúdos específicos de sua área através de aportes teóricos, mas é necessário que ele tenha a experiência de aplica-los na prática, o autor Libâneo (1990) propõe que o conhecimento que o estudante adquire deve ser aproveitado para a aquisição de novos conhecimentos, tendo assim, a legitimação de seus saberes. Ou seja, este estudante irá conseguir adquirir novas informações sobre o mesmo conceito quando ele conseguir trabalhá-los na prática.

Segundo Saviani (1996, p.154):

A teoria exprime interesses, objetivos e finalidades, se posicionando a respeito de qual rumo à educação deve tomar sentido, a teoria não é 
apenas aquela que retrata ou faz constatação do existente, mas também é orientadora de uma ação que permita mudar a realidade. Quanto à prática educacional, ela é entendida como sendo sempre o ponto de partida e o ponto de chegada (SAVIANI, 1996, p.154).

De acordo com a afirmação de Saviani, é importante termos conhecimento da teoria para sabemos direcionar nossas aulas e orientar nossos alunos durante as aulas, pois se não conseguimos ter domínio sobre a teoria não iremos obter um processo de ensino e aprendizagem efetivado. Neste contexto, Tardif (2002, p.16), diz que o que chamamos de "teoria, de saber" ou de "conhecimento" existe somente por meio de um sistema de práticas e de atores que as produzem e as assumem.

Segundo Lunetta (1991) as aulas práticas contribuem no processo de interação e desenvolvimento de conceitos, bem como oportuniza aos alunos aprender como abordar objetivamente o seu mundo e desenvolver soluções para os problemas complexos. Nesse sentido, as aulas práticas no ensino de ciências proporcionam aos alunos um desafio na sua imaginação e no raciocínio.

\section{Contato inicial com a sala de aula}

Monteiro (2002, p. 141) destaca que durante a formação inicial, especificamente, ao cursar os componentes curriculares relacionados à Prática de Ensino, os futuros professores “[...] vivem um momento estratégico em sua vida profissional, vivenciando um ritual de passagem. Ele/ela é, ao mesmo tempo, aluno e professor, portanto tem a sensibilidade aguçada para perceber as repercussões da ação educativa com olhos de quem ainda se sente como aluno". Assim, podemos destacar que o primeiro contato com a sala de aula é importante para que os licenciados tenham a oportunidade de ser professor por um tempo, podendo entender melhor como funciona o ambiente escolar.

Conforme Santos e Nunes (2006), a escola é um espaço privilegiado para a formação, tanto de professores, como de alunos, pois é nela que se realiza um trabalho sistemático articulado ao conhecimento, valores, atitudes e formação de hábitos.

O contato inicial dos licenciados com a sala de aula é de extrema importância para processo de formação docente, pois oferece condições aos futuros educadores, uma relação próxima com o ambiente que envolve o cotidiano de um professor e, a partir desta experiência os acadêmicos começarão a se compreenderem como futuros 
professores pela primeira vez, encarando o desafio de conviver, falar e ouvir, com linguagens e saberes distintos do seu meio, mais acessível à criança (PIMENTA, 1997).

\section{Despertar o interesse dos alunos}

O professor na sala de aula é um guia, pois procura influenciar os seus estudantes para que estes se interessem pelas aulas, estejam atentos, participem, apresentem comportamentos adequados e obtenham bons resultados escolares (JESUS, 2008), é necessário que os professores estejam ciente de que o seu estudante poderá ter um aprendizado limitado e, para evitar que isso ocorra, ele deve proporcionar o conforto e bem estar que seus aprendizes necessitam. Assim, é preciso lembrar que cada estudante tem uma forma diferente de aprender.

Neste contexto Jesus (2008), explica que é importante analisar que fatores podem permitir aos professores influenciar os seus alunos ou, no mesmo sentido, o que é que leva os alunos a deixarem-se influenciar pelo professor. Dessa forma, a utilização de novas estratégias e metodologias, visando aproximar a química do cotidiano do aluno, tem permeado uma série de propostas didáticas, as quais chegam a se expressar, em diferentes níveis, nas salas de aulas reais de química e de ciências de um modo geral (FERREIRA; SILVA, 2011).

\section{METODOLOGIA}

A metodologia é entendida como o conhecimento crítico dos caminhos do processo científico, indagando e questionando acerca de seus limites e possibilidades. (Demo, 1989)

Esta pesquisa tem uma abordagem qualitativa, pois segundo Denzin e Lincoln (2006), a pesquisa qualitativa envolve uma abordagem interpretativa do mundo, logo os pesquisadores desta área estudam as coisas em seus cenários naturais, tentando entender os fenômenos em termos dos significados que as pessoas a eles conferem.

Além disto, a abordagem qualitativa está situada num universo de significados, de crenças, de valores e de atitudes. A realidade, então, deve ser interpretada e tentar expressar o sentido dos fenômenos do mundo social (GODOY, 1995). 
Vol. 4, n. 4. Mai./Ago. 2021

ISSN: 2595- 4520

\section{Metodologia}

A metodologia capaz de dar conta de aproximada

da

fala em seu contexto partir do seu interior e especificidade

em que é produzida

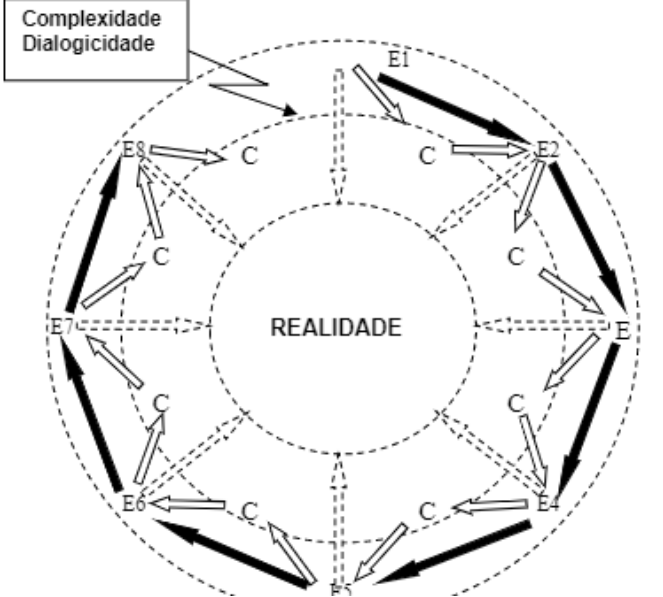

\section{interativa}

interativa é método uma interpretação realidade. Ele coloca a para entendê-la a no campo da histórica e totalizante, (OLIVEIRA, 2012).

$\mathrm{Na}$ metodologia interativa a coleta de dados é realizada pelo Círculo Hermenêutico-Dialético (CHD). Logo, as técnicas utilizadas se originam da mesma fonte teórica e filosófica e complementam-se no sentido de atingir coerentemente os objetivos propostos de investigação. De acordo com Oliveira (2012) a metodologia interativa permite uma participação efetiva de todos os envolvidos na pesquisa, eliminando-se ao máximo a subjetividade do pesquisador.

\section{Círculo hermenêutico-dialético e Sequência didática interativa}

O CHD não apresenta esquema fechado, conforme Guba e Lincoln (1989).

Fonte: Oliveira (2013)

Figura 1: Ilustração do Circulo Hermenêutico Dialético 
Ao tomar como referência Oliveira (2013), na figura 1, o primeiro círculo, representa o grupo de estudantes que serão entrevistados. O segundo, a dinâmica do "vai e vem" das construções/reconstruções teóricas dos sujeitos e o terceiro (centro); exposição de comentários e nova construção, o que representa o encontro final com todos os entrevistados, buscando o consenso único (realidade) do grupo (OLIVEIRA, 2013). A seguir detalhamos a aplicação da SDI, seguindo os passos orientados por Oliveira (2013):

Inicialmente, elaboramos duas perguntas que está relacionada ao objetivo deste trabalho. São elas: Qual a importância do PIBID na sua formação inicial?; Na sua concepção, como o PIBID auxilia na compreensão dos conteúdos abstratos no ensino da química? Depois, selecionamos o local e os licenciados participantes do PIBID que fariam parte da entrevista através das suas disponibilidades e criamos nomes fictícios para os mesmos, assim garantimos a privacidade do entrevistado.

Logo após, entrevistamos e gravamos as respostas individuais da primeira participante Maria e fizemos a síntese de sua entrevista, que chamamos de E1. Para a participante Eva, com as mesmas perguntas feitas, apresentamos o a síntese E1, para acrescentar ou mudar algo, no final foi feita a síntese E2, o que chamamos de C1. Para a terceira participante Ana, repetindo a mesma entrevista, logo após mostramos a síntese das entrevistas E1 e E2 e o comentário C1, para que comentasse, após fizemos a síntese E3 e a síntese do comentário C2. E com o último participante João, repetimos a entrevista e mostramos as sínteses E1, E2, E3 e os comentários C1 e C2 para que ela comentasse e fizemos a síntese C3. Resaltamos que todas as entrevistas foram mantidas o sigilo de dos participantes. Foi realizado um encontro final com todos os participantes, entregamos todas as sínteses feitas (tanto das entrevistas, quanto dos comentários), pedimos que lessem com calma e comentassem o que gostariam de acrescentar, discordar ou concordar das entrevistas anteriores, o que gerou uma discussão sobre alguns pontos que estavam descritos. Ao final deste encontro fizemos uma síntese final com auxílio da gravação.

Em relação à SDI vale salientar a importância da sondagem inicial para a construção dessas respostas "[...] que é resultante de um conhecimento que foi construído ao longo de suas experiências, cujas ideias foram assimiladas ao 
longo de sua existência/experiência sobre a temática que se pretende trabalhar no contexto da sala de aula [...]" (OLIVEIRA, 2013, p. 61).

\section{Universo da Pesquisa}

Esta pesquisa foi realizada no mês de junho de 2019, na Universidade Federal Rural de Pernambuco no Campus Unidade Acadêmica de Serra Talhada, os participantes da pesquisa foram quatro estudantes do curso de licenciatura em química da referida instituição e participantes do PIBID nas escolas que possuem parceria com a IES.

Os estudantes participantes da pesquisa foram escolhidos devido à disponibilidade para participar desta investigação, eles atuam na mesma escola, porém em diferentes turmas.

O primeiro entrevistado que chamaremos de Maria atua na turma do $1^{\circ}$ ano, o segundo entrevistado que chamaremos de Eva, atua na turma do $1^{\circ}$ ano, o terceiro entrevistado chamaremos de Ana e atua na turma do $2^{\circ}$ ano, e o quarto entrevistado chamaremos de João e atua na turma do $2^{\circ}$ ano.

\section{Análise Hermenêutica Dialética}

A Análise Hermenêutica Dialética nos proporciona analisar através de três possibilidades na pesquisa qualitativa: a análise de conteúdo, a análise do discurso e a hermenêutica-dialética (MINAYO, 2008). A autora ressalta que o método de análise é capaz de dar conta de uma interpretação da realidade.

Organização dos dados: Nesta etapa realizamos a leitura de todas as sínteses e a escuta dos áudios gravados nas entrevistas, após a leitura identificamos pontos articulados entre elas e com o referencial teórico escolhido a partir das respostas dos entrevistados.

Classificação dos dados: Nesta etapa foram separadas as falas segundo a ação dos sujeitos pesquisados. Segundo Oliveira (2011) a estruturação teórica e técnica da Metodologia Interativa ocorre com a criação das categorias teóricas, como referenciais para a construção dos instrumentos de pesquisa. Assim, na nossa pesquisa criamos as categorias de analise sugiram através dos dados obtidos nas concepções dos sujeitos de pesquisa sobre as questões propostas e o nosso referencial teórico, nos quadros abaixo 
temos as categorias e descrições. As categorias teóricas descritas no quadro 1, são elaboradas de acordo com o objetivo central, ou seja, resgatamos da literatura embasamentos teóricos para validar a pesquisa de acordo com a fala dos participantes, as categorias empíricas descrita no quadro 2, são os temas geradores que utilizamos para que os participantes discutam livremente sobre o tema em questão.

Quadro 1. Descrição das Categorias Teóricas.

\begin{tabular}{|l|l|}
\hline \multicolumn{1}{|c|}{ Categoria Teórica } & \multicolumn{1}{c|}{ Descrição } \\
\hline Relação teoria e prática & $\begin{array}{l}\text { As falas dos sujeitos que permeiam o tema relação teoria e prática } \\
\text { dos licenciandos de química, e outros temas que se articulem com } \\
\text { eles. }\end{array}$ \\
\hline Contato inicial com a sala de aula & $\begin{array}{l}\text { As falas dos sujeitos que permeiam o tema contato inicial com a } \\
\text { sala de aula referente aos licenciandos e outros temas que se } \\
\text { articulem com eles. }\end{array}$ \\
\hline Despertar o interesse dos alunos & $\begin{array}{l}\text { Nesta categoria, as falas permeiam sobre o tema despertar o } \\
\text { interesse dos alunos que permeiam na disciplina de química, e } \\
\text { outros temas que se articulem com eles. }\end{array}$ \\
\hline
\end{tabular}

\section{Fonte: Própria}

Quadro 2. Descrição das Categorias Empíricas.

\begin{tabular}{|c|c|}
\hline Categoria Empírica & Descrição \\
\hline $\begin{array}{l}\text { Importância do PIBID na sua } \\
\text { formação inicial }\end{array}$ & $\begin{array}{l}\text { Nesta categoria, os participantes discutem como o PIBID teve } \\
\text { importância para sua formação inicial enquanto docente. }\end{array}$ \\
\hline $\begin{array}{l}\text { Explicação de como o PIBID } \\
\text { auxilia na compreensão dos } \\
\text { conteúdos abstratos no ensino de } \\
\text { química }\end{array}$ & $\begin{array}{l}\text { As falas dos sujeitos que permeiam sobre como eles acreditam que } \\
\text { o PIBID irá auxiliar os alunos do ensino básico a compreender } \\
\text { melhor os assuntos considerados abstratos pelos estudantes } \\
\text { trabalhado na disciplina de química. }\end{array}$ \\
\hline
\end{tabular}

Fonte: Própria

\section{RESULTADOS E DISCUSSÃO}

Para facilitar a compreensão do leitor, apresentamos os resultados divididos em categorias, relação teoria e prática, contato inicial com a sala de aula e despertar o interesse dos alunos. Esta pesquisa são apresentados três categorias teóricas, descritas no quadro 1 e 2 . Enfatizamos que os resultados são apresentados de acordo com as falas dos atores sociais dentro das categorias. Nesse sentido, as categorias empíricas só aparecem quando estão relacionadas com as categorias teóricas.

Os quadros 3, 4 e 5, trazem as respostas dos participantes da pesquisa e estes estão organizados em categoria teórica, categoria empírica e o sujeito.

Categoria: Relação teoria e prática 
Quadro 3. Relação teoria e prática.

\begin{tabular}{|c|c|c|c|}
\hline $\begin{array}{c}\text { Categoria } \\
\text { teórica }\end{array}$ & $\begin{array}{l}\text { Categoria } \\
\text { empírica }\end{array}$ & Sujeito & Unidade de análise \\
\hline \multirow{3}{*}{$\begin{array}{c}\text { Relação teoria e } \\
\text { prática }\end{array}$} & $\begin{array}{l}\text { Importância do } \\
\text { PIBID na sua } \\
\text { formação inicial }\end{array}$ & Eva & $\begin{array}{l}\text { "Ter a oportunidade de vivenciar na prática } \\
\text { o que apenas aprendemos na teoria na } \\
\text { Universidade [...]" }\end{array}$ \\
\hline & $\begin{array}{lr}\text { Explicação } & \text { de } \\
\text { como o } & \text { PIBID } \\
\text { auxilia } & \text { na } \\
\text { compreensão } & \text { dos } \\
\text { conteúdos } & \\
\text { abstratos } & \text { no } \\
\text { ensino de química }\end{array}$ & Ana & $\begin{array}{l}\text { [...]ter essa vivência escolar ao mesmo } \\
\text { tempo que estuda os conteúdos das } \\
\text { disciplinas de ensino na Universidade faz } \\
\text { com que o discente tenha essa } \\
\text { representação, do que o docente fala nas } \\
\text { aulas, melhorando sua compreensão[...] }\end{array}$ \\
\hline & $\begin{array}{l}\text { Importância do } \\
\text { PIBID na sua } \\
\text { formação inicial }\end{array}$ & João & $\begin{array}{l}\text { [...]Tornando possível a criação de um } \\
\text { vínculo entre as teorias que são abordadas } \\
\text { durante a graduação com as experiências } \\
\text { vivenciadas na sala de aula.[...] }\end{array}$ \\
\hline
\end{tabular}

Fonte: Própria

Nesta categoria falamos claramente o quanto é importante o PIBID na formação dos licenciando, onde Eva ressalta que o programa deu a oportunidade dela vivenciar as teorias aprendidas em sala de aula na prática, dentro da escola, ensinando aos alunos e participando do processo de ensino e aprendizagem desta escola, e é isto que Saviane (1996) fala, que é importante dominar as teorias especificas aprendidas na sala de aula, para assim desenvolver no exercício da prática em um contexto educativo.

Além disto, Ana e João relatam que é importante estudar o conteúdo na universidade, e ao mesmo tempo aplicar no ensino básico, assim como Tardiff (2002) diz que o discente está conseguindo relacionar a teoria trabalhada em aula e colocando em prática, como também Libâneo (1990) cita que ao mesmo tempo que o licenciado está aprendendo o conteúdo e aplicando na sala de aula, ele estará adquirindo novos conhecimentos, para assim obter uma compreensão mais aguçada sobre os conteúdos.

Assim, podemos notar a importância que os alunos ressaltam de estar relacionando a teoria que se estuda em suas graduações, com a prática de aplica-las em sala de aula, tendo a experiência enquanto professores, esta oportunidade que o PIBID proporciona é bem reconhecida pelos estudantes das licenciaturas.

Categoria: Contato inicial com a sala de aula

Quadro 4. Contato inicial com a sala de aula.

\begin{tabular}{|c|c|c|c|}
\hline $\begin{array}{c}\text { Categoria } \\
\text { teórica }\end{array}$ & $\begin{array}{c}\text { Categoria } \\
\text { empírica }\end{array}$ & Sujeito & Unidade de análise \\
\hline & Importância do & Maria & "O PIBID me proporcionou o meu contato \\
\hline
\end{tabular}




\begin{tabular}{|c|c|c|c|}
\hline \multirow{4}{*}{$\begin{array}{l}\text { Contato inicial } \\
\text { com a sala de } \\
\text { aula }\end{array}$} & $\begin{array}{l}\text { PIBID na sua } \\
\text { formação inicial }\end{array}$ & & $\begin{array}{l}\text { inicial em sala de aula, através dele } \\
\text { desenvolvi habilidades que até então eram um } \\
\text { desafio para mim.[...]." }\end{array}$ \\
\hline & $\begin{array}{l}\text { Importância do } \\
\text { PIBID na sua } \\
\text { formação inicial }\end{array}$ & Eva & $\begin{array}{l}\text { [...] proporcionar aos bolsistas a construção } \\
\text { do conhecimento adquirido através de } \\
\text { experiências na prática em sala de aula.[...] }\end{array}$ \\
\hline & $\begin{array}{l}\text { Importância do } \\
\text { PIBID na sua } \\
\text { formação inicial }\end{array}$ & Ana & $\begin{array}{l}\text { [...]pois da à oportunidade do discente de se } \\
\text { inserir no contexto escolar no início da } \\
\text { graduação, coisa que ele só teria no final nos } \\
\text { estágios.[...] }\end{array}$ \\
\hline & $\begin{array}{l}\text { Importância do } \\
\text { PIBID na sua } \\
\text { formação inicial }\end{array}$ & João & $\begin{array}{l}\text { [...] torna possível a qualificação do futuro } \\
\text { docente, os Pibidianos, pois por meio do } \\
\text { programa, da interação em sala de aula, é } \\
\text { possível a identificação das dificuldades que } \\
\text { são enfrentadas tanto pelo Professor quanto } \\
\text { pelo aluno.[...] }\end{array}$ \\
\hline
\end{tabular}

Fonte: Própria

Nesta categoria podemos ver relatos sobre o primeiro contato dos licenciando com a sala de aula, Maria diz que o PIBID proporcionou além deste primeiro contato o desenvolvimento de habilidades que eram difíceis para sua realidade, e João também resalta que é possível visualizar as dificuldades enfrentadas pelo professor e pelo aluno dentro da sala de aula, e é o que Pimenta (1997) fala que este contato dá a oportunidade do discente a enfrentar desafios da realidade escolar, em conviver com os alunos e poder fazer parte da realidade do que é ser professor.

Eva diz que o PIBID dá a oportunidade de adquirir experiências através das aulas, e é isto que Santos e Nunes (2006) defendem, que é necessário que haja esta interação para que seja originado novos hábitos para os licenciados, para que assim eles possam ir criando uma sistematização das responsabilidades que iram enfrentar ao tornar-se professor e ao assumir uma sala de aula na integra.

Enquanto Ana ressalta que o PIBID deu a oportunidade dela ser inserida no contexto escolar no inicio do seu curso, o que ela só iria poder fazer no final do curso na disciplina de estágio, levantando mais este ponto positivo sobre o programa, e Manteiro (2002) fala que é importante que isto ocorra, pois ao mesmo tempo que o licenciando está sendo aluno, ele está em sala de aluna sendo professor, logo irá aprender ainda mais sobre suas práticas docentes.

E é neste contexto que podemos observar que o PIBID proporciona em vários aspectos experiências positivas para os pibidianos, pois assim eles conseguem obter umas maior experiência em seu contato inicial com sala de aula, conseguir desenvolver 
estratégias de ensino e sistematização de seu papel enquanto professor, para assim vivenciar um estagio bem efetivado e ao ingressar no mercado de trabalho seja um professor crítico-reflexivo e inovador, que visa melhorar cada vez mais a educação básica e está sempre comprometido com a aprendizagem do aluno.

Categoria: Despertar o interesse dos alunos

Quadro 5. Despertar o interesse dos alunos.

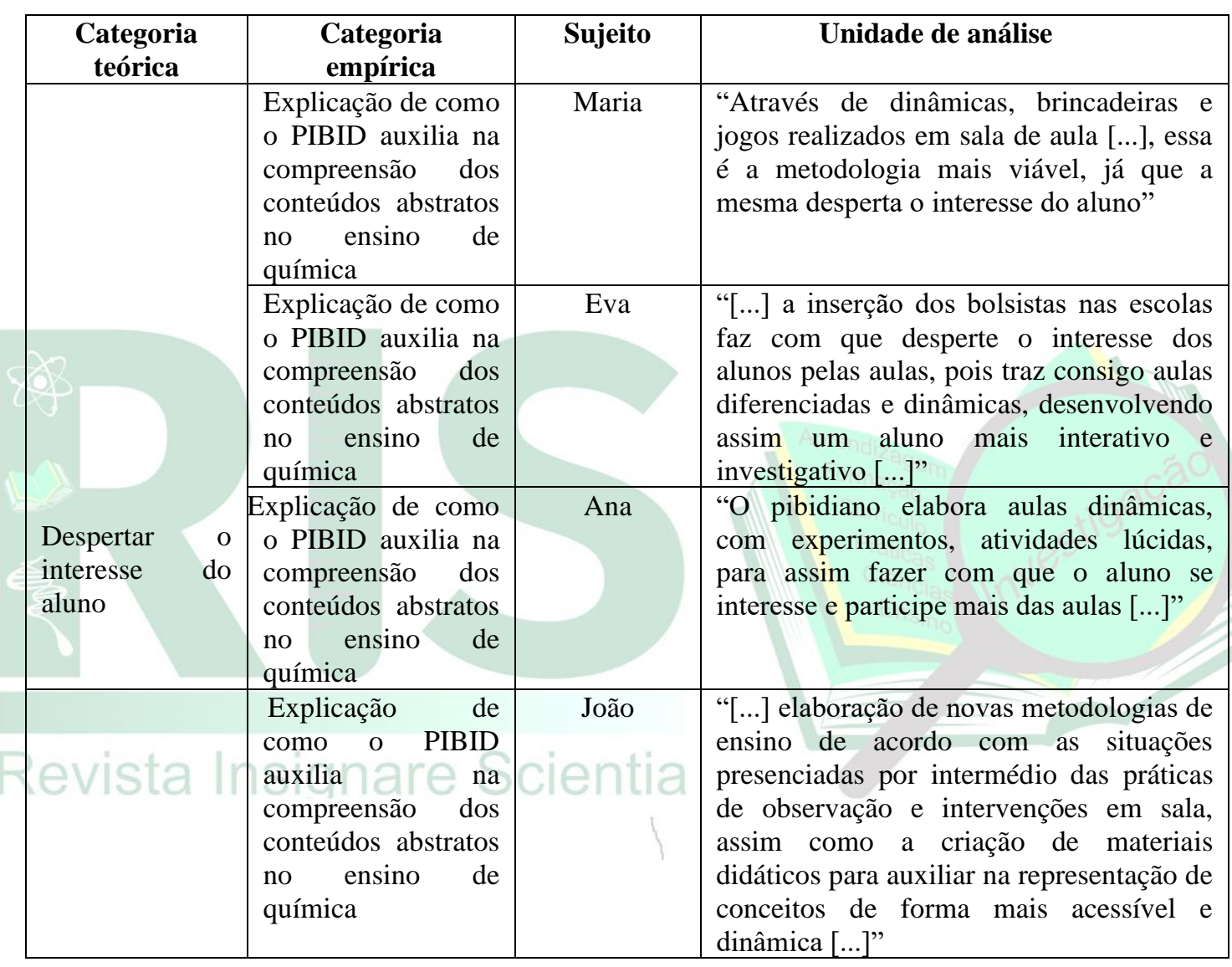

Fonte: Própria

Nesta categoria falamos sobre o que desperta o interesse dos estudantes em sala de aula. Maria, Eva, Ana e João, ambas abordam a questão de aulas dinâmicas em sala como foco do interesse dos alunos. Silva e Ferreira (2011) afirmam que a utilização de novas estratégias e metodologias, auxiliam e inspiram os estudantes pelo conteúdo. Assim como Jesus (2011), explica que este fato permite que os alunos estejam atentos, participem e apresentem comportamentos adequados.

Eva e Ana, dizem que esse destaque com aulas diferenciadas vem com os pibidianos/bolsistas. Silva, Falcomer e Porto (2018), afirma que o objetivo central do 
PIBID é a inclusão das diversas atividades que proporcionam a aprendizagem a partir de diferentes instrumentos e metodologias de ensino, estimulando a docência através de intervenções realizadas. É nesse contexto que os pibidianos trazem um diferencial para as aulas, onde na maioria das vezes os professores por vários motivos não conseguem diferenciar muito em suas aulas, assim como tem uma grande quantidade de turmas para dá conta.

\section{CONSIDERAÇÕES FINAIS}

Os resultados obtidos nesta pesquisa mostra a importância que o PIBID tem para os pibidianos em sua formação, assim como a relevância do que propõe em sala de aula. Com relação ao tópico teoria e prática, foi possível identificar que os bolsistas entendem que a experiência enquanto professora é uma oportunidade única que o PIBID proporciona para as licenciaturas.

No tópico contato inicial com a sala de aula, foi observado que o PIBID propicia em vários aspectos experiências positivas, como o contato inicial com sala de aula, a habilidade em desenvolver estratégias de ensino e sistematização de seu papel enquanto professor, vivenciando na pratica e compreendo a vida de professor, para ser críticoreflexivo e inovador, visando melhorar cada vez mais a educação básica.

Além disto, nos mostra o quanto o PIBID é importante no ensino da química para que os alunos tenham uma visão mais abertas sobre os conteúdos e é isto que trazemos no último tópico, onde relatamos o despertar do interesse do aluno, que os pibidianos relaram que fazem um diferencial nas aulas, com destaque das aulas dinâmicas que motivam os estudantes, assim facilita a compreensão de assuntos abstratos no ensino da química. 


\section{REFERÊNCIAS}

BELO, E.S.V. Professores formadores de professores de matemática. $2012.150 \mathrm{f}$.

Dissertação (Programa de Pós- Graduação em Educação em Ciências e Matemáticas). Instituto de Ciências Matemáticas e Científicas, Universidade Federal do Pará, Belém, 2012.

BRANCO, E.; ZANATTA, S. BNCC e Reforma do Ensino Médio: implicações no ensino de Ciências e na formação do professor. Revista Insignare Scientia - RIS, v. 4, n. 3, p. 58-77, 2021.

CHASSOT, A. I. A Educação no Ensino de Química; Livraria Inijuí Editora; Rio Grande do Sul, 1990.

CUNHA, R. S. et al. Formação inicial docente e suas relações dentro do âmbito escolar. Ciência \& Educação, Bauru, v. 22, n.3, p. 585-596, 2016.

CUSTODIO, C.M.S. A formação inicial do professor e a função da escola-campo de estágio: desafios e possibilidades. In: IX Seminário em Educação da Região Sul, 9.; 2012, Pelotas. Anais... IX ANPED Sul, 2012. P. 1-16.

DEMO, P. Metodologia do conhecimento científico. São Paulo: Atlas, 2000.

DENZIN, Norman K.; LINCOLN, Yvonna. A disciplina e a pratica da pesquisa qualitativa. In:DENZIN, Norman K.; LINCOLN, Yvonna (orgs). Planejamento da pesquisa qualitativa: teorias e abordagens. 2 ed. Porto Alegre: ARTMED, 2006.

FERREIRA, W. M.; SILVA, A. C. T. As fotonovelas no ensino de química. Química Nova na Escola, v. 33, n. 1, p. 25, 2011.

FORMOSINHO, J.; FERREIRA, F. I. Concepções de professor: diversificação, avaliação e carreira docente. In: FORMOSINHO, João (Org.). Formação de professores:

aprendizagem profissional e acção docente. Porto, Portugal: Porto Editora, 2009, p. 19 -36.

FREIRE, P. Extensão ou comunicação? Comunicação? 17. ed. São Paulo: Paz e Terra, 2015.

FREIRE, P. Pedagogia da Autonomia: saberes necessários à prática educativa. 15. ed. São Paulo: Paz e Terra, Coleção Leitura, 1999.

GARCIA, C.M. O professor iniciante, a prática pedagógica e o sentido da experiência. Revista Brasileira de Pesquisas sobre Formação Docente, Belo Horizonte, v. 02, n. 03, p. 11-49, 2010.

GODOY, A. S. Introdução à pesquisa qualitativa e suas possibilidades. In: Revista de Administração de Empresas, v. 35, n. 2, mar/abril, 1995, p. 57-63. 
JESUS, S. N. Estratégias para motivar os alunos. Educação, Porto Alegre, v. 31, n. 1, p. 2129, 2008.

LIBÂNEO, J. C. Democratização da escola pública. São Paulo: Loyola, 1990.

LUNETTA, V. N. Actividades práticas no ensino da Ciência. Rev. Portuguesa Educ., v.2, p. 81-90, 1991.

MASSENA, E.P.; SIQUEIRA, M. Contribuições do PIBID à formação inicial de professores de ciências na perspectiva dos licenciandos. Revista Brasileira de Pesquisa em Educação em Ciências, v. 16, n. 1, p. 17-34, 2016.

MINAYO, M. C. S. O desafio do conhecimento: pesquisa qualitativa em saúde. 8.ed. São Paulo: Hucitec, 2008.

MONTEIRO, A. M. A prática de ensino e a produção de saberes na escola. In: CANDAU, V. M. (org). Didática, currículo e saberes escolares. 2. ed. Rio de Janeiro: DP\&A, 2002.

MOYSÉS, L. M. O desafio de saber ensinar. $2^{a}$ edição. Campinas, SP : Papirus. Riode Janeiro, RJ: Ed. da Universidade Federal Fluminense, 1995.

MORETTO, R.; LIMA, J.; GUIDORZI, M.; AFFONSO, H. Formação de Professores e Educação Ambiental: desafios e conquistas no contexto imposto pela Pandemia de Covid19. Revista Insignare Scientia - RIS, v. 4, n. 3, p. 291-308, 2021.

OLIVEIRA, M. M. Sequência didática interativa no processo de formação de professores. Petrópolis (RJ): Vozes, 2013.

OLIVEIRA, M. M.. Complexidade e Dialogicidade trabalhadas no processo de Formação de Professores. Recife: Editora Universitária da UFRPE, Vol. 250, p. 13-25, 2012.

PAREDES, G. G. O.; GUIMARÃES, O. M. Compreensões e significados sobre o PIBID para a melhoria da formação de professores de Biologia, Física e química. Química Nova Escola, Curitiba, v. 34, n. 4, p. 266-277, 2012.

PIMENTA, Selma Garrido. O estágio na formação de professores: unidade, teoria e prática? 3.ed. São Paulo: Cortez, 1997

PRIESS, E. Y. Didática no Ensino Superior. edição1, Sociesc, Joinville-SC, 2012.

RIO GRANDE DO SUL. Secretaria de Estado da Educação do Rio Grande do Sul. Proposta Pedagógica para o Ensino Médio Politécnico e Educação Profissional integrada ao Ensino Médio (2011-2014). out./nov. 2011.

SANTOS, A. B. G., Avaliação das dificuldades enfrentadas no processo de ensino e aprendizagem da disciplina de química na educação de jovens e adultos. Trabalho de Conclusão de Curso (Graduação em Licenciatura em Química) - Universidade Federal Rural de Pernambuco. Unidade Acadêmica de Serra Talhada, p. 13, jan. 2019.

SANTOS, C. F.; NUNES, M. F. A indisciplina no cotidiano escolar. Candombá - Revista Virtual. v. 2, n. 1, p. 14-23, jan./ jun. 2006. Disponível em: 
<http://revistas.unijorge.edu.br/candomba/2006v2n1/pdfs/MarinildesNunes2006v2n1.pdf> Acesso em: 06 jun. 2019.

SAVIANI, D.A. Educação: do censo comum à consciência filosófica. Campinas: Autores Associados, 1996.

SCHNETZLER, R. Um estudo sobre o tratamento do conhecimento químico em livrosdidáticos dirigidos ao ensino secundário de Química de 1875 a 1978. Química Nova,v.4, n.1, p.6-15, 1981.

SILVA, D.G. Desenho e aplicação de uma sequência de ensino-aprendizagem sobre os princípios da teoria cognitivista da aprendizagem multimídia (TCAM). 2017. 105F. Dissertação (Programa de Pós-Graduação em Ensino das Ciências). Universidade Federal Rural de Pernambuco, Recife, 2017.

SILVA, D. M. S.; FALCOMER, V. A. S.; PORTO, F. S. As contribuições do PIBID para o desenvolvimento dos saberes docentes: A experiência da Licenciatura em Ciências Naturais, Universidade de Brasília . Revista Ensaio, Belo Horizonte. v.20, 2018.

SILVA, S. G. As principais dificuldades na aprendizagem de química na visão dos alunos do ensino médio. IX Congic, p. 1612-1616, julho 2013.

TARDIF, Maurice. Princípios para guiar a aplicação dos programas de formação inicial para o ensino. In: EGGERT, E. et al. Trajetórias e processos de ensinar e aprender: didática e formação de professores (textos selecionados do XIV ENDIPE). Porto Alegre: EDIPUCRS, 2008, p. 17-46.

TARDIF, Maurice. Saberes docentes e formação profissional. Petrópolis: Vozes, 2002. USBERCO, J; SALVADOR, E. Química Essencial, volume único, Saraiva, São Paulo-SP, 2007.

VALENTE, N., Didática: ferramenta cotidiana do professor, 2009. Disponível em: $<\mathrm{http} / / \mathrm{www}$.jornaldedebates.uol.com.br/debate/como-melhorar-qualidade-educacaonobrasil/artigo/didatica-ferramenta-cotidiana-professor>. Acesso em: 26 mar. 2019.

VASCONCELOS, T.C., ROCHA, J.S., Dificuldades de aprendizagem no ensino de química: algumas reflexões, XVIII EncontroNacional de Ensino de Química (XVIII ENEQ) Florianópolis, SC, Brasil -25a 28 de julho de 2016. Disponivel em: http://www.eneq2016.ufsc.br/anais/resumos/R0145-2.pdf

VEIGA, M. S. M.; QUENENHENN, A.; CARGNIN C., O ENSINO DE QUÍMICA: algumas reflexões, I JORNADA DE DIDÁTICA -O ENSINO COMO FOCO -I FÓRUM DE PROFESSORES DE DIDÁTICA DO ESTADO DO PARANÁ,UTFPR, 2012. 